\title{
FISIOTERAPIA
}

\section{Desenlaces en los niveles del ácido láctico en sangre en personas sanas expuestas a masaje terapéutico vs estiramiento muscular posterior a la práctica del ejercicio físico}

\author{
Omar Ramiro Morelos Páez , Julián Hernández Quintero
}

\section{Resumen}

Introducción: El ácido láctico es un producto de desecho, comúnmente producido tras el proceso catabólico de los carbohidratos al producir ATP, sin embargo, en la actualidad presente una gran controversia, debido a que se ha demostrado que éste no solo es resintetizado como combustible para la producción de energía, sino que también es necesario en reposo.

Debido a esto, se hace necesario investigar un poco sobre cómo a través de ciertas técnicas fisioterapéuticas se puede ayudar al músculo a movilizarlo al torrente sanguíneo con mayor rapidez para contribuir con la aceleración de mi proceso metabólico. Por esto, se presenta el siguiente estudio que comparó el masaje vs el estiramiento para acelerar la resitetización del lactato posejercicio. Objetivo: Determinar los desenlaces en los niveles del ácido láctico en sangre en personas sanas expuestas a masaje terapéutico vs estiramiento muscular posterior a la práctica del ejercicio físico en un grupo de usuarios del Centro de Acondicionamiento Físico de la Escuela Colombiana de Rehabilitación.

Material y Método: Esta investigación fue desarrollada con un total de 41 sujetos, de los cuales se excluyeron16. En total 25 pacientes fueron escogidos para el estudio quienes se aleatorizaron en los diferentes grupos de interés (control, $n=8$; estiramiento, $n=7$; masaje, $n=10$ ). A la muestra seleccionada, se le realizó un procedimiento que consistió en la aplicación de instrumentos de medición de la condición física e historia clínica, posteriormente, se hicieron tomas de ácido láctico pre-ejercicio, posejercicio y post-estrategia de intervención fisioterapéutica. A todos los grupos se les aplicó un protocolo de entrenamiento físico, basado en los lineamientos establecidos para la prescripción de ejercicio según el ACSM 2014.

Resultados: Los datos recolectados expresan diferencias estadísticamente significativas entre las medias de los niveles de lactato sérico entre los

1. Fundación Escuela Colombiana de Rehabilitación, Colombia.

E-mail: omorelos@ecr.edu.co

DOI: 10.26885/rcei.foro.2019.223

Trabajo publicado en acceso abierto bajo Licencia Creative Commons. 
diferentes grupos, obteniéndose valores $p<0,05$. Lo que se traduce en un aumento importante del lactato en sangre post-ejercicio en cada uno de los grupos estudiados. En la regresión lineal múltiple se obtienen resultados que expresan una baja relación entre las variables independientes y la variable dependiente, en donde el coeficiente de determinación es cercano a cero $\left(R^{2}\right.$ $=0.01$ ), indicando una correlación débil sin significancia estadística $(p=0,8)$.

Conclusiones: Se puede concluir que, en los tres grupos de estudio los niveles de lactato presentaron un incremento en su concentración en sangre posrealización de ejercicio físico, sin embargo, una de las estrategias generó una mayor respuesta que la otra. Dado el evento, los datos presentan insuficiencia estadística que permita identificar cuál de las estrategias de intervención es más efectiva, sin embargo, los datos expresan un aumento en los niveles de lactato en los sujetos de estudio expuestos al masaje terapéutico con respecto a los demás grupos. Es posible que las estrategias de intervención favorezcan el proceso de eliminación o resintetización del ácido láctico, por lo tanto, es importante aclarar que, dado el tamaño de la muestra, los datos pueden tener mayor relevancia estadística en futuros estudios cuya muestra sea representativa.

Palabras clave: ácido láctico, masaje, estiramiento muscular.

\section{Referencias}

ACSM. (2006). M. Resource Manual for Guidelines for Exercise Testing and prescription. Philadelphia: Lippincott Williams and Wilkins.

Biriukov, A. (2003). Masaje meportivo. Ed. Paidotribo.

Heyward, V. H. (2006). Evaluación y prescripción del ejercicio. Barcelona, España: Paidotribo.

López Chicharro, J. (2006). Fisiología del ejercicio. Ed. Panamericana.

Sanchez, C., Ruiz, Y., Martin, M. C. (2008). Influencia del lugar de extracción en la determinación de los niveles de lactato durante una prueba de esfuerzo incremental. Madrid: Revista Elsevier. 